\title{
Mapeamento de Áreas de Risco Associadas ao Carste em Área Urbana no Município de João Pessoa-PB
}

\author{
Mapping of Risk Areas Associated with Karst in Urban Area of the Municipality \\ of João Pessoa-PB
}

\author{
Caio Lima dos Santos ${ }^{1}$ \\ Osvaldo Girão da Silva ${ }^{2}$ \\ Saulo Roberto de Oliveira Vital ${ }^{3}$
}

\author{
Palavras-chave: \\ João Pessoa-PB \\ Riscos Geomorfológicos \\ Carste urbano
}

\begin{abstract}
Resumo
No município de João Pessoa existem feições do relevo formadas por processos cársticos, denominadas depressões fechadas. A dinâmica natural do relevo cárstico é governada pelo processo de dissolução das rochas, principalmente dos carbonatos. As características geológicas identificadas e as condições relativas à evolução do relevo no referido município o colocam numa condição de área suscetível a ocorrência de processos cársticos, que, soma-se ao forte processo de urbanização observado na área. Assim, este artigo teve como objetivo identificar e caracterizar formas de relevo desenvolvidas por processos de carstificação, visando possibilitar a análise de riscos nestes ambientes, considerando, além da susceptibilidade natural, os aspectos relacionados às formas de usos e ocupação urbana. Para tanto, foram mapeadas feições de relevo cárstico, denominadas depressões fechadas. Foi elaborado mapa de suscetibilidade aos processos de carstificação por meio da técnica álgebra de mapas, considerando como fatores as condições estruturais, a litologia e a geomorfologia, assim como as condições de ocupação urbana. Por fim, os dados obtidos foram sobrepostos, tendo como produto final a classificação de áreas de risco associadas a processos cársticos. Foi verificado que a condição estrutural representa o fator preponderante para as condições de risco observadas no município de João Pessoa, estado da Paraíba, além dos impactos introduzidos no sistema cárstico em função das atividades antrópicas, que por vezes representam o gatilho para ocorrência de fenômenos como a abertura de crateras em área urbana.
\end{abstract}

\begin{abstract}
The city of João Pessoa has relief features formed by karstic processes, called closed depressions. The natural dynamics of the karst relief is dominated by the process of dissolution of rocks, especially carbonates. The geological characteristics identified, and the conditions related to the evolution of the relief in the city place it in an area susceptible to the occurrence of karst processes, which adds to the strong urbanization process observed in the area. Thus, this article aimed to identify and characterize landforms developed by karstification processes to enable the analysis of risks in these environments, considering, in addition to natural susceptibility, aspects related to forms of urban uses and occupation. For this purpose, we mapped features of karst relief, called closed depressions. A map of susceptibility to karstification processes was created by using the map algebra technique, considering the factors of structural conditions, lithology, and geomorphology, as well as the conditions of urban occupation. Finally, the generated data were superimposed producing the classification of risk areas associated with karstic processes. The structural condition has been found to represent the preponderant factor for the risk conditions in the city of João Pessoa, Paraíba state, in addition to the impacts introduced in the karst system due to human activities, which sometimes represent the trigger for the occurrence of phenomena such as the opening of craters in urban areas.
\end{abstract}




\section{INTRODUÇÃO}

$\mathrm{Na}$ geomorfologia cárstica o processo de dissolução representa o gatilho para o desenvolvimento de formas típicas do relevo cárstico, tais como depressões fechadas e dolinas. Estes ambientes apresentam superfícies de solos irregulares e zonas de dissolução que podem eventualmente formar zonas de subsidência (GUTIÉRREZ et al., 2014).

Os riscos em áreas cársticas, por vezes, são originados direta ou indiretamente por ações antrópicas, que podem desencadear impactos que podem ter consequências imprevisíveis devido às peculiaridades características dos ambientes cársticos, que apresentam hidrodinâmica subsuperficial específica, o que exige a adoção de métodos específicos, considerando os fatores condicionantes do ambiente cárstico e a dinâmica antrópica (DE WAELE et al., 2011; GUTIÉRREZ et al., 2011, TRAVASSOS, 2011; LOBO, 2013; GUTIÉRREZ, 2016; NAWAZ et al., 2020; GOMES et al., 2021).

Em áreas urbanas as alterações superficiais decorrentes das atividades antrópicas ganham maior notoriedade, se revelando quase sempre na ocorrência de situações de risco, que por seu turno causam danos materiais e humanos aos habitantes destas localidades. Nos ambientes cársticos as alterações urbanas ganham destaque ainda maior, tendo em vista a alta sensibilidade do sistema às mudanças na dinâmica hidrológica (DE WAELE et al., 2011; HUANG et al., 2020), quase sempre representada pela desconexão da drenagem superficial com a subsuperfície devido ao soterramento de depressões cársticas, onde observa-se a ocorrência de lagoas, ou pela introdução de fluxo turbulento no sistema devido ao rompimento de condutos de abastecimento de água ou rompimento de galerias pluviais. Além destes aspectos ocorre também o aumento da acidez dos fluxos em trânsito no sistema hidrológico do carste em área urbana em função da disposição de efluentes domésticos e/ou industriais no solo (VESTENA et al., 2002).

O planejamento de ações a serem realizadas na superfície devem considerar as características de subsuperfície, no intuito de mitigar os impactos (GUTIÉRREZ et al., 2014). Os mesmos autores afirmam ainda que a construção de edificações sobre essas feições alteradas pode conduzir a ocorrência de danos a sociedade, pois as modificações ocorridas em feições preexistentes podem conduzir ao entendimento destas áreas como estáveis do ponto de vista dos riscos, como é o caso de depressões soterradas no processo de urbanização.

O rebaixamento do nível da água em função do processo de impermeabilização de depressões fechadas pode provocar a perda do suporte hidrostático que, assim como o sobrepeso de edificações no teto de cavidades cársticas, podem ocasionar a subsidência do terreno, configurando um fator de risco para populações residentes (PEREIRA, 1998). Outros fenômenos como colapsos, subsidências do solo, alagamentos e inundações estão relacionados a evolução de um carste, podendo trazer riscos para a população que ocupa estas áreas, uma vez que a atuação de tais fenômenos pode comprometer a estrutura de variadas modalidades de edificações (LOLCAMA, 2002; MARÉCHAL et al., 2008; ZENG e HUANG, 2018).

Essa problemática é observada no município de João Pessoa, estado da Paraíba, e representa aspecto relevante das suas características geoambientais. A dinâmica geomorfológica que caracteriza a área do referido município sofre influência direta de processos subsuperficiais decorrentes de suas características geológicas/geomorfológicas (FURRIER et al., 2006; VITAL, 2015; VITAL et al., 2020). Sua área territorial está assentada sobre a Bacia Sedimentar Paraíba que, dentro de seus limites, apresenta estratigrafia disposta em camadas de rochas de origem marinha (Calcário da Formação Gramame) e terrígenas (arenitos da Formação Beberibe/Itamaracá). Recobrindo estas camadas estão os sedimentos da Formação Barreiras, constituída predominantemente por sedimentos argilosos (BARBOSA, 2007).

A Bacia Sedimentar da Paraíba apresenta ocorrência de depressões cársticas associadas a manifestações superficiais e subsuperficiais de carbonatos, estando sua origem relacionada ao processo de dissolução atuante nos calcários da formação Gramame (VITAL, 2015; VITAL et al., 2020).

Situações de risco em João Pessoa são geradas em função das condições naturais favoráveis que o relevo cárstico proporciona, associadas ao forte processo de urbanização observado no município a partir da segunda metade do século XX, caracterizado pelo crescimento urbano horizontal rápido $\mathrm{e}$ inadequado (RODRIGUEZ, 1980).

Isto posto, têm-se como objetivo deste artigo identificar áreas de risco associadas às características dinâmicas do ambiente cárstico no município de João Pessoa. Para tanto, foram considerados aspectos relativos às condições físico-naturais que caracterizam o relevo cárstico na área municipal, bem como as que 
foram observadas a partir dos aspectos da urbanização e os fatores geradores do risco.

\section{PROCEDIMENTOS METODOLÓGICOS}

A princípio foi realizada a delimitação e mapeamento das depressões fechadas. Este procedimento foi realizado com auxílio do software Global Mapper, com base no Modelo Digital de Elevação (MDE) gerado a partir de imagens do sensor de varredura a laser LiDAR (Light Detection And Ranging) capturada no ano de 2012, com resolução espacial de dois metros, cedidas pela Secretaria de Planejamento da Prefeitura Municipal de João Pessoa SEPLAN/PMJP (2020), a partir da seguinte rotina de trabalho: extração automática das drenagens; geração automática de curvas de nível com equidistância de dois metros; delimitação manual das bacias fechadas com base nas drenagens e nas curvas de nível.

A elaboração do mapa de suscetibilidade aos processos cársticos considerou três aspectos: condições estruturais, espessura da camada rochosa capeadora em relação a camada rochosa carbonática e geomorfologia.

O mapa de lineamentos e alinhamento das depressões fechadas foi elaborado com base no MDE e no alinhamento espacial das feições mapeadas, respectivamente. Este procedimento consiste na vetorização manual de estruturas lineares (drenagens) identificadas neste modelo de elevação e na vetorização de linhas retas interligando as depressões, com auxílio do software QGIS 3.14 (2021). Posteriormente, os dados vetoriais foram exportados para o software Spring 5.5.6 (1996) onde foram geradas rosetas de direções preferenciais para os lineamentos identificados e o alinhamento das depressões.

O mapa geológico do município de João Pessoa foi adaptado a escala de trabalho adotada nesta pesquisa, equivalente a 1:100.000, a partir do mapa elaborado pela CPRM no ano de 2002 na escala 1:500.000, desenvolvido para o estado da Paraíba. A realização deste procedimento considerou a compartimentação do relevo a partir do MDE utilizado na pesquisa.

A espessura das formações rochosas foi verificada a partir do processo de interpolação de dados referentes à altimetria dessas camadas na Bacia Sedimentar Paraíba. Estes dados foram extraídos de documentos que contém informações referentes a topografia das camadas litológicas descritas em dados de poços tubulares, que foram coletados a partir da plataforma do Sistema de Águas Subterrâneas SIAGAS (sd), do Serviço Geológico do Brasil CPRM (2019), Companhia de Águas e Esgotos da Paraíba - CAGEPA (2015), Agência Executiva de Águas - AESA (2015).

Este procedimento consiste na construção de uma tabela que contém os dados descritos utilizando o programa Microsoft Excel (2016). Posteriormente esta tabela foi importada para o software Surfer 12 (2014), onde foi realizado o processo de interpolação e geração de um modelo de superfície para cada camada litológica. Em seguida foram verificados os valores topográficos desse modelo, e procedeu-se a reclassificação desses valores e a atribuição de pesos para cada grupo reclassificado no software ArcMap 10.4 (ESRI, 2016). Os referidos modelos de elevação foram sobrepostos ao mapeamento das feições estudadas, com o intuito de verificar se a ocorrência de depressões superficiais estava associada a depressões subsuperficiais.

A geomorfologia foi analisada com base no mapeamento geomorfológico para o município de João Pessoa proposto por Barbosa (2015). Este mapa foi sobreposto ao mapa das feições selecionadas para esse estudo. Assim, no processo de reclassificação e atribuição de pesos para cada classe geomorfológica considerou-se maior peso para as classes onde ocorrem as depressões fechadas selecionadas para este estudo.

Por fim, os valores reclassificados de cada variável considerada na análise da suscetibilidade foram submetidos ao processo de "álgebra de mapas" através da ferramenta "calculadora raster" do software ArcMap 10.4 (ESRI, 2016). Esse processo consiste na ponderação de valores atribuídos a cada variável, obtendo-se como resultado o mapa de suscetibilidade a processos cársticos que, por sua vez, com base nas informações consideradas e nos valores a elas atribuídas, indicam os locais que estão mais suscetíveis a manifestação de processos cársticos. Em seguida este dado foi transformado do formato matricial para o formato vetorial, para possibilitar o cálculo de área de cada classe de suscetibilidade e a sobreposição ao cadastro urbano do município de João Pessoa.

A análise dos riscos foi realizada com base nos seguintes procedimentos: sobreposição do mapa de suscetibilidade natural ao cadastro urbano do município de João Pessoa; definição de classes de risco geomorfológico; verificação e descrição de campo; aplicação de ficha de campo.

A sobreposição do mapa de suscetibilidade natural ao cadastro urbano foi realizada com auxílio do software ArcMap 10.4 (ESRI, 2016), procedendo, inicialmente, a adequação dos 
dados a um mesmo sistema de referência. Em seguida, realizou-se o recorte do shape referente aos dados do cadastro urbano com base nas classes de suscetibilidade e a contabilidade do quantitativo de residências inseridas dentro dessas áreas, a partir da tabela de atributos do dado analisado, por meio da técnica de superposição cartográfica.

\section{RESULTADOS E DISCUSSÃO}

\section{Mapeamento das depressões Fechadas}

Foram identificadas e mapeadas um total de 13 (treze) depressões fechadas (Quadro 01). De modo geral, todas as depressões ocorrem sobre os sedimentos da Formação Barreiras, que por sua vez representa a manifestação geológica superficial predominante no referido município, havendo alguns pontos onde é observada a ocorrência superficial das Formações Gramame e Beberibe (Figura 01).

Quadro 01 - localização das depressões mapeadas.

\begin{tabular}{|c|c|c|}
\hline Depressão & Coordenadas UTM & Endereço \\
\hline 01 & $\begin{array}{l}290.611,849 / \\
9.207 .492,087\end{array}$ & Três lagoas, Bairro Oitizeiro. \\
\hline 02 & $\begin{array}{l}293.157,140 / \\
9.211 .753,969\end{array}$ & Lagoa do Parque Sólon de Lucena, Bairro Centro \\
\hline 03 & $\begin{array}{l}294.725,749 / \\
9.212 .553,072\end{array}$ & Av. Epitácio Pessoa, Bairro dos Estados / Expedicionários \\
\hline 04 & $\begin{array}{l}289.812,746 / \\
9.205 .893,881 \\
\end{array}$ & Avenida das Indústrias, Distrito Industrial \\
\hline 05 & $\begin{array}{l}291.203,777 / \\
9.209 .741,413\end{array}$ & $\begin{array}{c}\text { Lagoa Antônio Lins, Av. Doutor Antônio Lins, Bairro Cruz } \\
\text { das Armas }\end{array}$ \\
\hline 06 & $\begin{array}{l}290.641,446 / \\
9.206 .189,845\end{array}$ & Rua Henrique Nascimento, Bairro Costa e Silva \\
\hline 07 & $\begin{array}{l}291.174,181 / \\
9.208 .143,208\end{array}$ & Lagoa do Buracão, Av. Ana Nery, Oitizeiro \\
\hline 08 & $\begin{array}{l}288.658,486 / \\
9.210 .185,360\end{array}$ & Rua Francisco José das Neves, Bairro Alto do Matheus \\
\hline 09 & $\begin{array}{l}289.220,818 / \\
9.208 .172,804\end{array}$ & Rua Luiz Barbalho, Bairro Jardim Veneza \\
\hline 10 & $\begin{array}{l}293.334,718 / \\
9.212 .049,933\end{array}$ & Av. Camilo de Holanda, Bairro Centro. \\
\hline 11 & $\begin{array}{l}290.108,710 / \\
9.203 .822,132 \\
\end{array}$ & Via Perimetral Sul, Bairro Gramame. \\
\hline 12 & $\begin{array}{l}292.742,790 / \\
9.206 .663,387\end{array}$ & Rua José Lins Sobrinho, Bairro João Paulo II \\
\hline 13 & $\begin{array}{l}290.345,481 / \\
9.204 .177,289\end{array}$ & Via Perimetral Sul, Bairro Gramame. \\
\hline
\end{tabular}

Fonte: Os autores (2021).

Conforme é verificado na (Figura 04), a ocorrência de depressões fechadas na área de estudo está condicionada a menor espessura da Formação Barreiras em relação à Formação Gramame, coincidindo com as superfícies de denudação, no que diz respeito a geomorfologia (Figura 05); além da ocorrência de estruturas lineares e falhamentos (Figura 03), representados pelo alinhamento estrutural destas feições. A sobreposição destas informações ao mapa das depressões fechadas indicam que a manifestação superficial destas feições do relevo se associa à conjugação destes fatores. 
Figura 01 - Mapa geológico do município de João Pessoa.

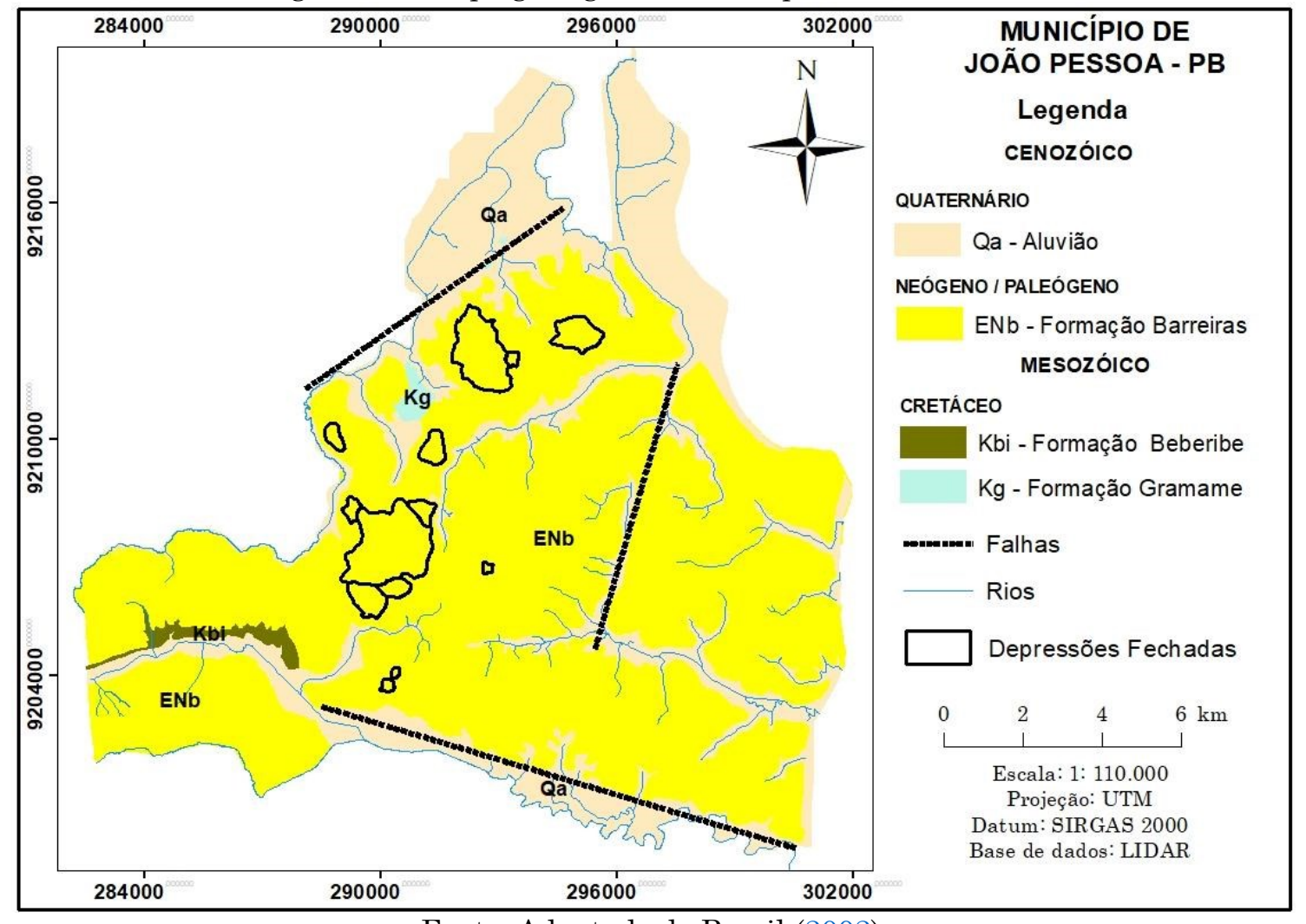

Fonte: Adaptado de Brasil (2002).

\section{Análise da Dinâmica Natural}

A classificação de áreas de risco geomorfológico associadas a processos cársticos no município de João Pessoa partiu da análise dos fatores relativos a processos naturais responsáveis pela gênese e evolução de feições deste tipo de relevo. Desse modo, foram considerados os seguintes fatores naturais: geologia, no que diz respeito à espessura da camada sedimentar capeadora (Formação Barreiras) sobre a camada rochosa carbonática (Formação Gramame); aspectos estruturais; e a geomorfologia. Considerando estes fatores, foi elaborado o mapa de suscetibilidade natural aos processos cársticos (Figura 02), no intuito de indicar as áreas onde os fenômenos genéticos e evolutivos do relevo cárstico podem ser mais ativos. 


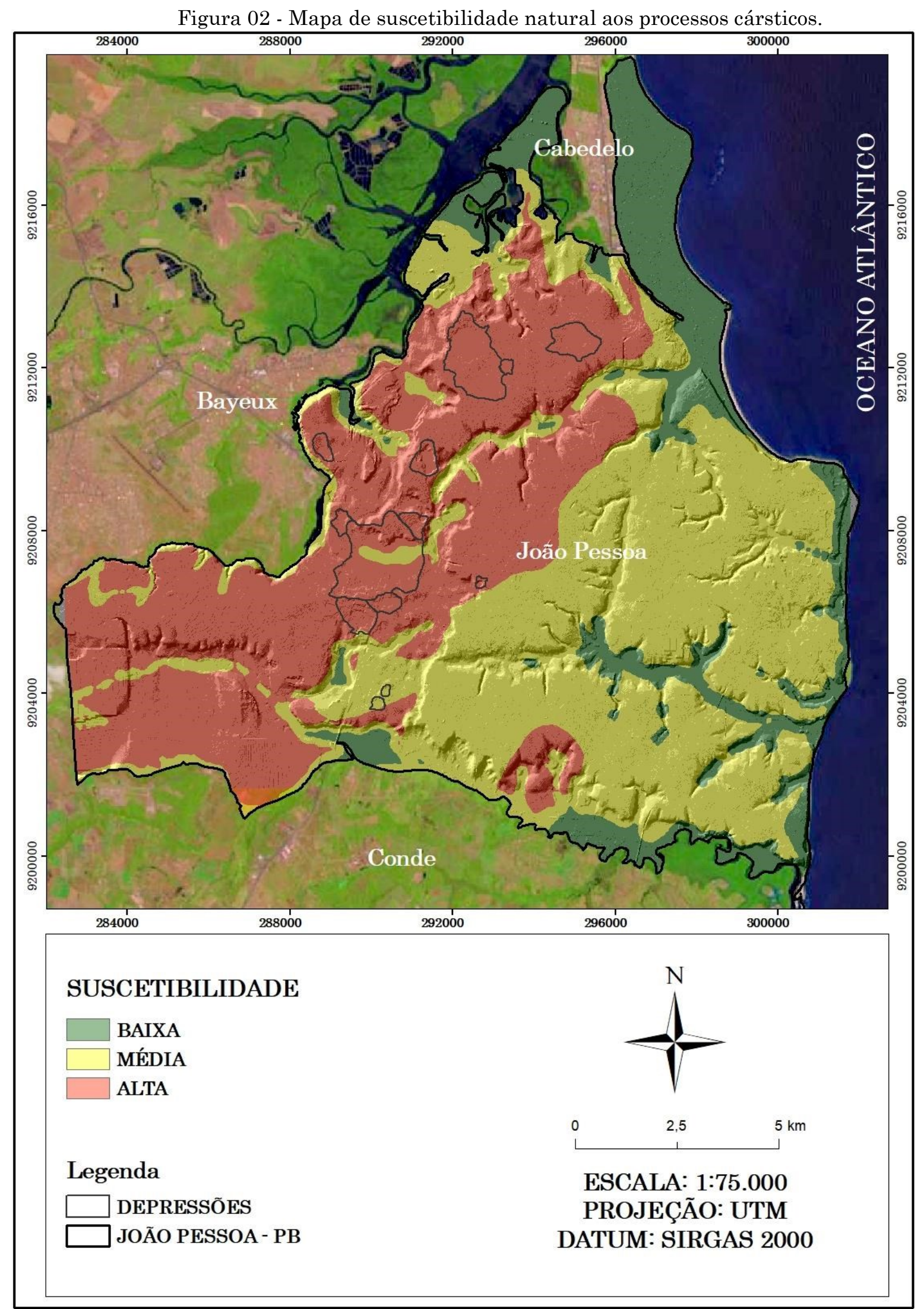

Fonte: Os autores (2021).

Para tanto, foram atribuídos pesos aos fatores analisados, conforme a Tabela 01, por meio da álgebra de mapas 
Tabela 01 - Pesos atribuídos aos fatores de suscetibilidade analisados.

\begin{tabular}{|c|c|}
\hline Fator Analisado & Peso \\
\hline Geomorfologia & 0,50 \\
\hline Altimetria da F. Gramame & 0,25 \\
\hline Espessura da F. Barreiras & 0,25 \\
\hline Total & 1,0 \\
\hline
\end{tabular}

Fonte: Os autores (2021).

Considerando o alinhamento das depressões fechadas mapeadas e as condições estruturais observadas para a área de estudo, compreendese que as condições estruturais (Figura 03) representa o "gatilho" para o processo carstificação. As áreas localizadas entre as depressões representam aquelas que estão sob influência direta das condições estruturais, uma vez que é nas linhas de fraqueza das rochas que os fluidos superficiais encontram maior facilidade para percolar, promovendo o respectivo processo de dissolução.

Figura 03 - Lineamentos estruturais e alinhamento das depressões fechadas no município de João Pessoa.

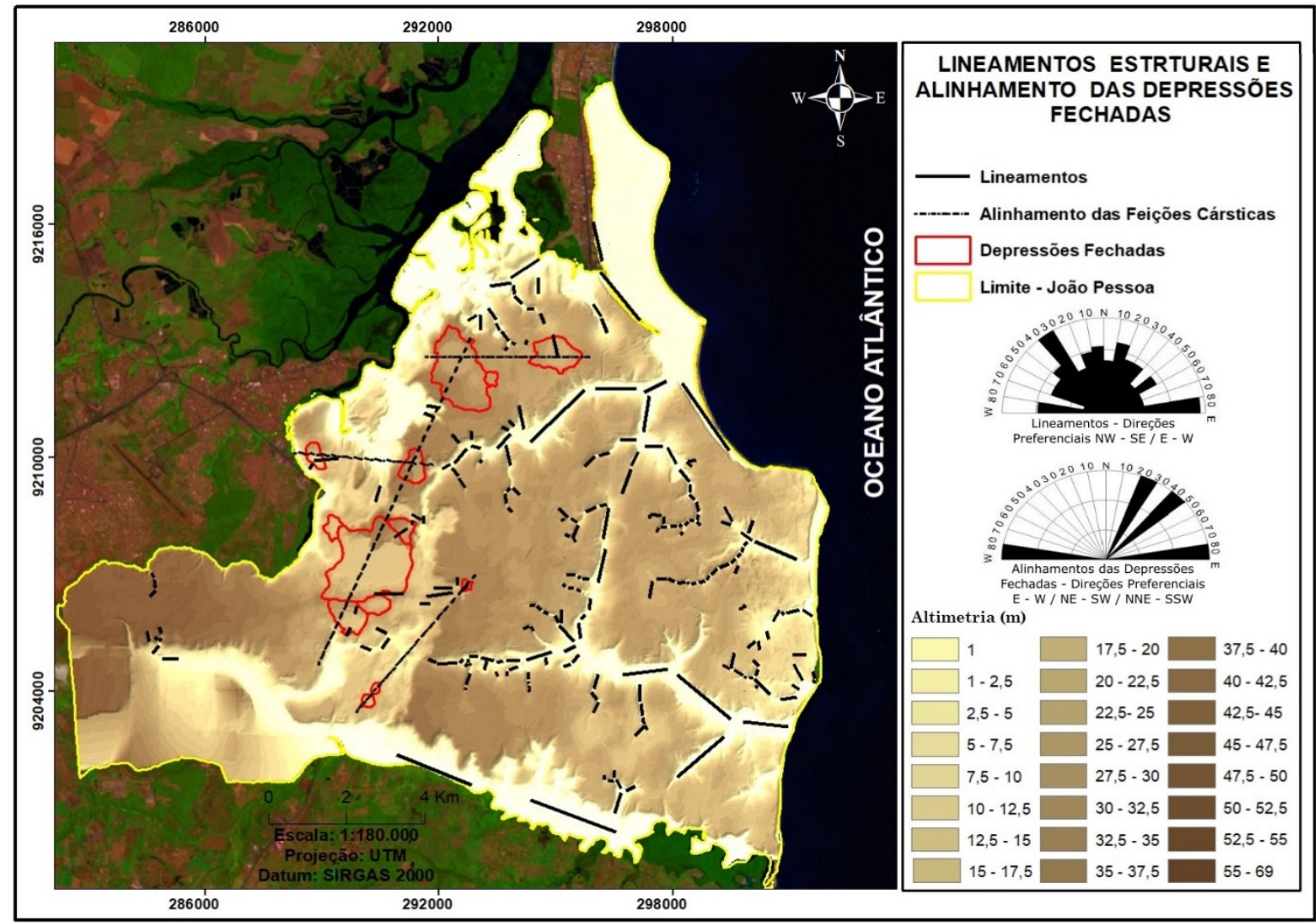

Fonte: Os autores (2021).

Com relação a espessura da camada litológica que capeia as rochas carbonática (Figura 04), considerou-se que a menor espessura da Formação Barreiras permite maior contato dos fluxos superficiais com as rochas da Formação Gramame. Nessas áreas é observado a maior proximidade das rochas carbonáticas ao nível base e até mesmo a ocorrência de afloramentos em alguns locais. Desse modo, foi atribuído peso $(0,25)$ a estes dois fatores, considerando a coincidência entre a menor espessura da Formação Barreiras e a menor profundidade da Formação Gramame. 
Figura 04 - Espessura das Formações Barreiras e Gramame medida em metros (m).

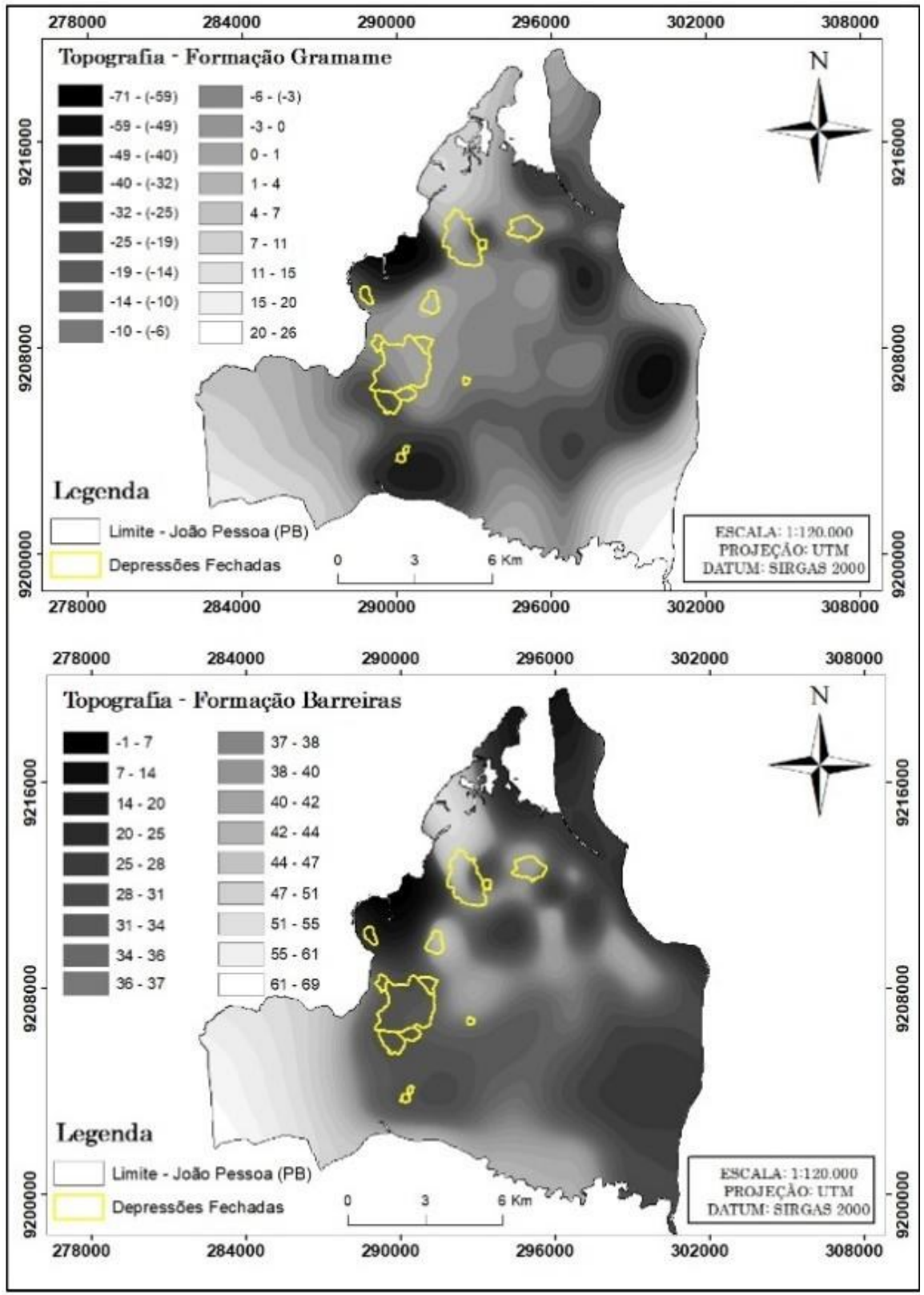

Fonte: Os autores (2021).

A geomorfologia (Figura 05) foi atribuído peso $(0,50)$, considerando-o como o fator de maior relevância na análise, pois todas as depressões ocorrem na superfície de denudação com formas convexas e na superfície de denudação com formas tabulares. 
Figura 05 - Geomorfologia do município de João Pessoa/PB

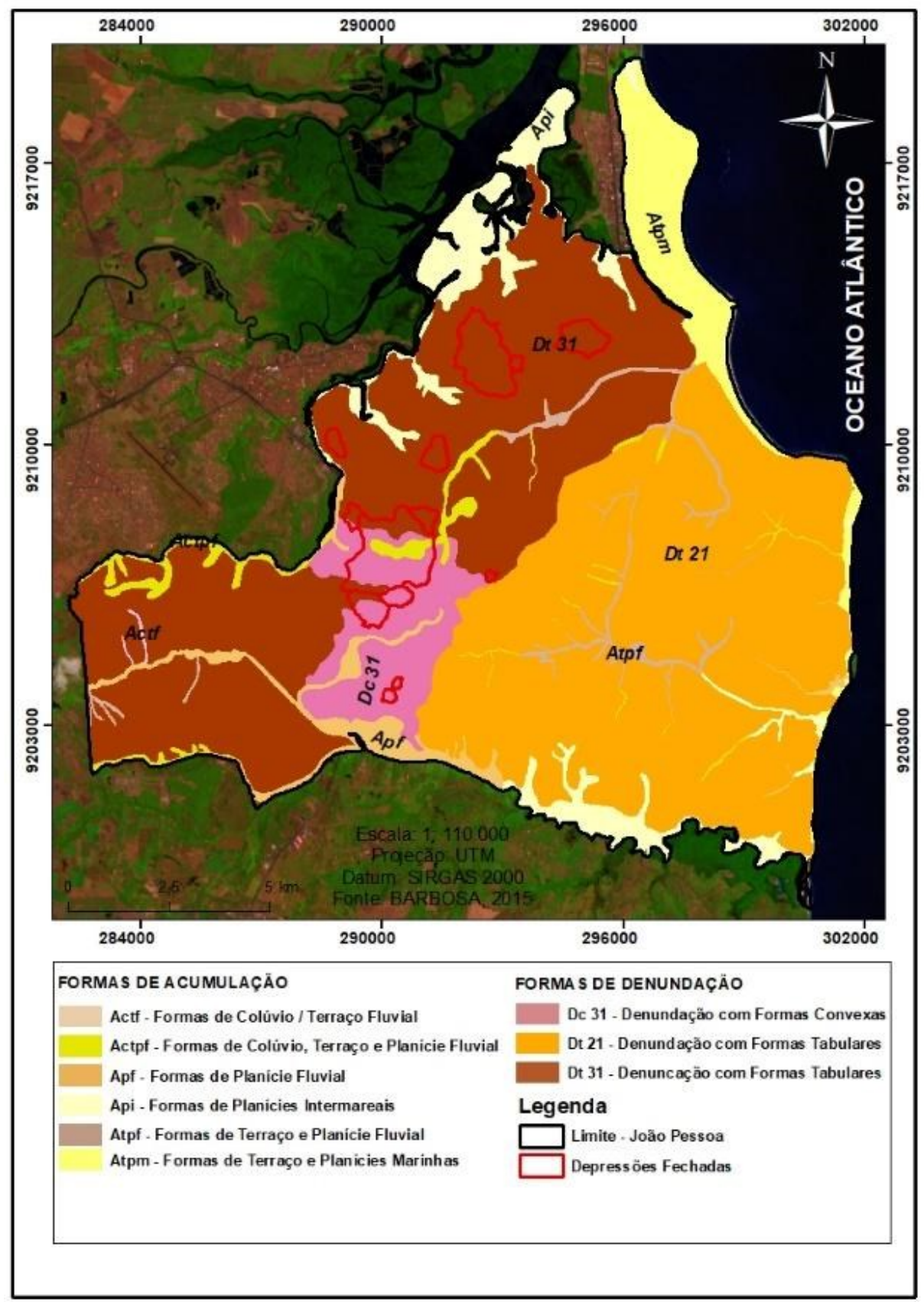

Fonte: Adaptado de Barbosa (2015).

Cada fator considerado foi reclassificado, atribuindo-lhes pesos variando de 1 a 3 , de acordo com sua relevância na análise da suscetibilidade (Figura 02), conforme a Tabela 02.

A espessura da Formação Barreiras foi divida em 3 classes, atribuindo-lhe peso 1 onde a variação se deu entre 50 e 116 metros; peso 2 onde a variação se deu entre 25 e 50 metros; peso 3 onde a espessura desta camada não ultrapassa 25 metros (Tabela 02).
Com relação a altimetria da Formação Gramame, foi atribuído maior peso (3) a variação altimétrica estabelecida entre 0 e 25 metros, considerando que quanto mais próximo à superfície a rocha carbonática estiver, maior será o seu contato com os fluxos superficiais. Tendo por base esta ideia, foi atribuído peso 2 à variação altimétrica entre -40 e 0 metros e peso 1 à variação altimétrica entre -70 e -40 metros (Tabela 02). 
Tabela 02 - Pesos atribuídos às classes temáticas de cada fator analisado.

\begin{tabular}{|c|c|c|c|}
\hline Peso & $\begin{array}{c}\text { Espessura F. } \\
\text { Barreiras }\end{array}$ & $\begin{array}{c}\text { Espessura F. } \\
\text { Gramame }\end{array}$ & Geomorfologia \\
\hline $\mathbf{1}$ & $50-116 \mathrm{~m}$ & $(-70)-(-40) \mathrm{m}$ & $\begin{array}{c}\text { Atpm / Api / Apf / } \\
\text { Actpf }\end{array}$ \\
\hline $\mathbf{2}$ & $25-50 \mathrm{~m}$ & $(-40)-0 \mathrm{~m}$ & $\mathrm{Dt} 21$ \\
\hline $\mathbf{3}$ & $0-25 \mathrm{~m}$ & $0-25 \mathrm{~m}$ & $\mathrm{Dt} 31 / \mathrm{Dc} 31$ \\
\hline
\end{tabular}

Actf - Formas de Colúvio / Terraço Fluvial; Actpf - Formas de Colúvio, Terraço e Planície Fluvial; Apf - Formas de Planície Fluvial; Api - Formas de Planícies Intermareais; Atpf - Formas de Terraço e Planície Fluvial; Atpm - Formas de Terraço e Planícies Marinhas; Dc 31 - Denudação com Formas Convexas; Dt 21 - Denudação com Formas Tabulares; Dt 31 - Denunciação com Formas Tabulares. Fonte: Barbosa (2015).

Como a área de ocorrência das feições mapeadas coincidem com superfícies de denudação (Dt 31 e Dc 21), estes compartimentos geomorfológicos receberam valor máximo 3; a classe definida como (Dt 21) constitui um compartimento geomorfológico de denudação com formas tabulares, onde a rede de drenagem apresenta-se mais densa, se comparado com o compartimento (Dt 31). A área de ocorrência desse compartimento também coincide com a área de maior espessura da Formação Barreiras, sendo esse o critério utilizado para a atribuição do peso 2 a esse fator.

Foi atribuído peso 1 às demais formas identificadas no mapeamento geomorfológico adotado nessa pesquisa (Atpm / Api / Apf / Actpf), considerando a não ocorrência de feições cársticas nesses compartimentos.
Análise dos aspectos relativos a ocupação humana

Foram verificados os aspectos relativos a ocupação humana e as alterações superficiais impostas decorrentes do processo de urbanização, bem como os problemas físicos observados nas estruturas prediais localizadas dentro das áreas onde os processos cársticos são mais ativos.

No Quadro 02 são descritos os efeitos causados no sistema cárstico decorrentes de alterações introduzidas pela dinâmica natural e pelas ações antrópicas observadas no município de João Pessoa (PB). Considerando esses aspectos é possível inferir situações que potencializam nesses ambientes a ocorrência de fenômenos que podem afetar o cotidiano social, configurando situações de risco. 
Quadro 02 - Fatores condicionantes para elaboração de situações de risco em ambiente cárstico observados no município de João Pessoa/PB.

\begin{tabular}{|c|c|c|c|}
\hline Fator & Efeito & $\begin{array}{c}\text { (1)Processo } \\
\text { natural } \\
\text { (2)Atividades } \\
\text { humanas }\end{array}$ & Área de atuação \\
\hline $\begin{array}{l}\text { Suscetibilidade } \\
\text { natural. }\end{array}$ & $\begin{array}{c}\text { Formação natural das } \\
\text { depressões fechadas. }\end{array}$ & $\begin{array}{l}\text { (1) Clima; } \\
\text { Condições } \\
\text { estruturais; } \\
\text { Litologia } \\
\text { carbonática; } \\
\text { Geomorfologi } \\
\text { a }\end{array}$ & $\begin{array}{c}\text { Município de João } \\
\text { Pessoa/PB }\end{array}$ \\
\hline $\begin{array}{l}\text { Impermeabilização } \\
\text { do solo. }\end{array}$ & $\begin{array}{l}\text { - Diminuição da infiltração } \\
\text { da água no solo; } \\
\text { - Rebaixamento do lençol } \\
\text { freático; } \\
\text { - Diminuição da pressão } \\
\text { hidrostática. }\end{array}$ & (2) Urbanização & $\begin{array}{c}\text { Evidente em todas } \\
\text { as feições } \\
\text { estudadas }\end{array}$ \\
\hline Escavações & $\begin{array}{l}\text { - Causa erosão interna } \\
\text { favorecida pelos buracos, } \\
\text { vibrações, fluidos de } \\
\text { perfuração e } \\
\text { bombeamento. } \\
\text { - Pode induzir fluxos de } \\
\text { águas subterrâneas } \\
\text { localizadas e turbulentas. }\end{array}$ & $\begin{array}{l}\text { (2) Introdução de } \\
\text { galerias pluviais. }\end{array}$ & Depressão 03 \\
\hline $\begin{array}{l}\text { Soterramento de } \\
\text { depressões }\end{array}$ & $\begin{array}{l}\text { - Desconexão da drenagem } \\
\text { superficial com a } \\
\text { drenagem subsuperficial; } \\
\text { - Rebaixamento do lençol } \\
\text { freático; } \\
\text { - Diminuição da pressão } \\
\text { hidrostática. }\end{array}$ & (2) Urbanização & $\begin{array}{c}\text { Depressões } 05,07 \\
\text { e } 09\end{array}$ \\
\hline $\begin{array}{l}\text { Impermeabilização } \\
\text { parcial da superfície }\end{array}$ & $\begin{array}{l}\text { - Aumento potencial do } \\
\text { escoamento superficial; } \\
\text { - Aumento do fluxo para o } \\
\text { interior da depressão; } \\
\text { - Erosão linear. }\end{array}$ & (2) Urbanização & Depressão 07 \\
\hline
\end{tabular}

Fonte: Os autores (2021).

As situações de risco no ambiente cárstico estão relacionadas a ocorrência de fenômenos geomorfológicos característicos desses ambientes, tais como a subsidência e o colapso do solo, quando repercutem no cotidiano social. Esses fenômenos representam etapa do processo de evolução natural do relevo cárstico, no entanto, as ações humanas podem alterar e/ou potencializar esses processos a partir de intervenções relacionadas às atividades como a exploração de água subterrânea, a irrigação, a disposição de efluentes nas depressões cársticas, a mineração, bem como o próprio processo de urbanização quando realiza as alterações superficiais necessárias para a ocupação.

A principal alteração produzida pela intervenção antrópica observada na área de estudo ocorre na conexão entre a drenagem superficial e o sistema cárstico, quando altera a dinâmica natural dos fluxos. Essa situação ocorre em dois momentos: entrada turbulenta de fluxo oriundo do sistema de galerias pluviais, devido ao rompimento dessa tubulação em função do rápido aumento de fluxo no sistema em situações de eventos chuvosos de alta magnitude; ou por meio do soterramento de lagoas. 
No primeiro caso a entrada turbulenta de fluxo promove a remoção mecânica do material desagregado de modo rápido, alargando os condutos verticais que conectam o sistema cárstico com a superfície, o que gera instabilidade no solo e o consequente abatimento do teto das cavidades subterrâneas (Figura 06). Essa situação é percebida com mais evidência no contexto da depressão 03 (Figura 01).

Figura 06 - (A) Cratera aberta no cruzamento das Avenidas Expedicionário e Júlia Freire.

(B) Cratera aberta na avenida Rio Grande do Sul, bairro dos Estados.

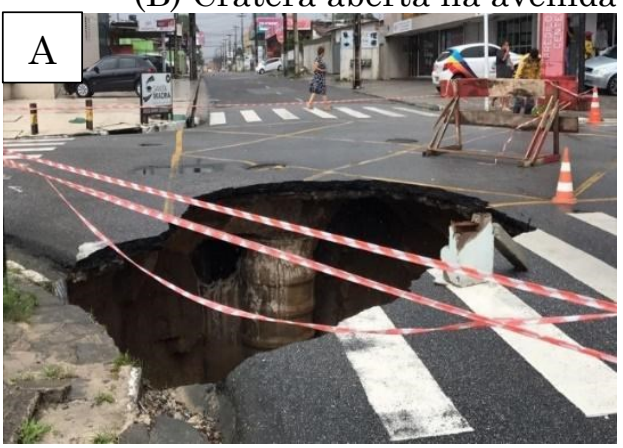

Fonte: Portal G1 Paraíba (2017).

No segundo caso, o soterramento das depressões onde ocorrem lagoas configura desconexão da drenagem superficial com o carste subjacente. O fluxo superficial é representado pelo direcionamento de fluido de origem pluvial para o ponto mais rebaixado das depressões fechadas, que se associa a pontos de afloramento do lençol freático. A desconexão dos fluxos superficiais e subsuperficiais, que nesse caso ocorre em função do soterramento de lagoas, provoca o rebaixamento do lençol freático e a diminuição da pressão hidrostática, resultando no consequente processo de subsidência lenta do solo.

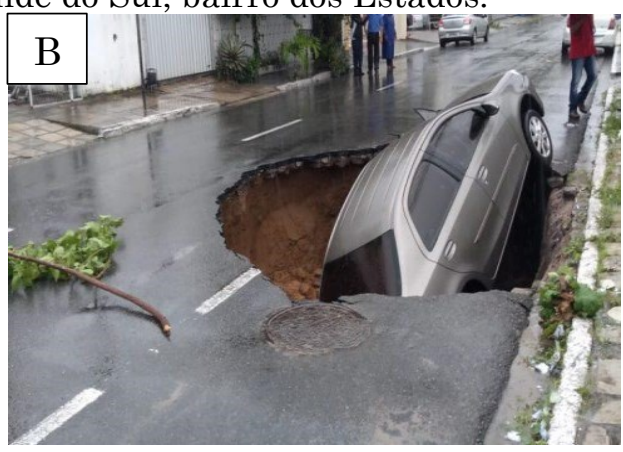

Fonte: LIRA (2019).

Nesse estudo foram identificados 4 (quatro) casos de soterramento de depressões fechadas e posterior ocupação urbana dessas áreas (depressões 05, 07, 09 e 12). Em todas elas foram verificados danos nas estruturas prediais (Figura 07), representados por rachaduras nas paredes e no piso, além de relatos de moradores sobre recorrentes eventos de afundamento do solo, provocando o desabamento de residências ou apenas de partes delas, o que evidencia a ocorrência do processo de subsidência do terreno nessa área. No caso da depressão 07 não foi observado o soterramento completo da lagoa, mas apenas de partes dela. 
Figura 7 - Rachaduras identificadas nas instalações prediais indicadas pelas setas nas imagens.

A) depressão 05; B) depressão 07; C) depressão 09; D) depressão 12.

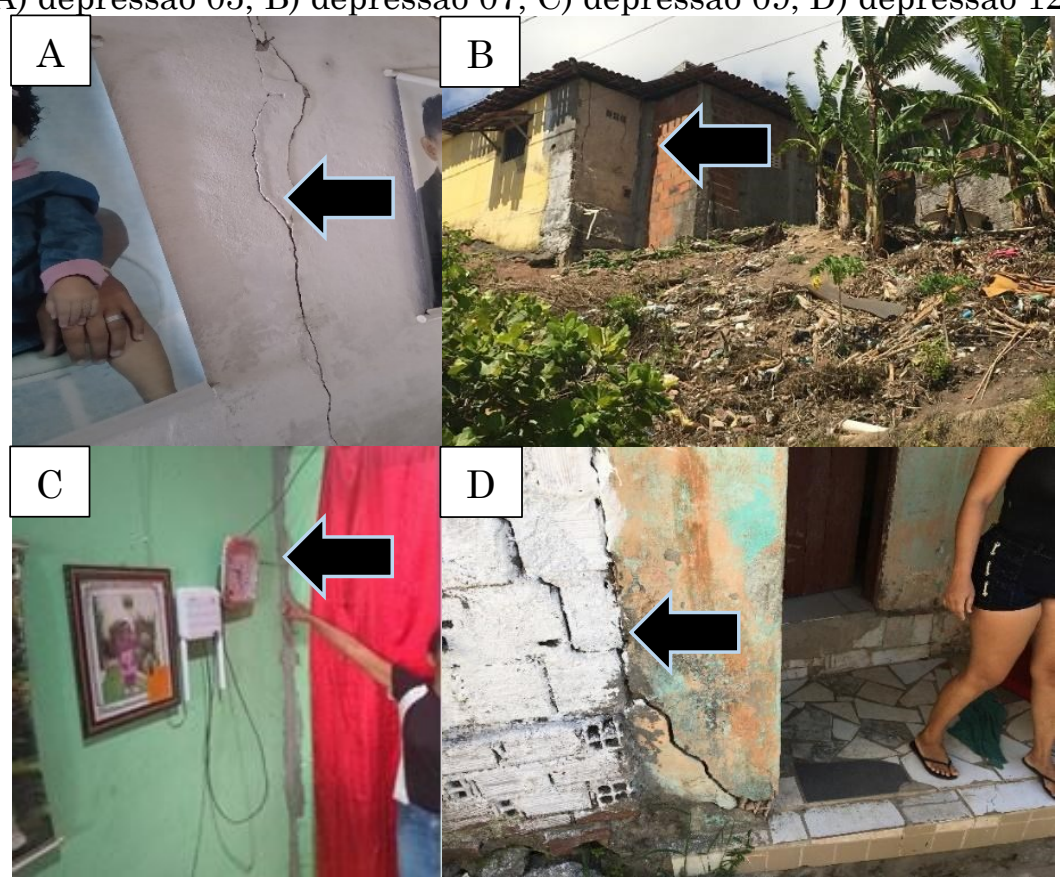

Fonte: Os autores (2021).

Considerando os problemas descritos nas depressões 03, 05, 07, 09 e 12, estas áreas foram classificadas como risco muito alto no mapa de risco (figura 08), uma vez que são nestas localidades que foram identificadas situações de risco com mais evidência.

Figura 08 - Mapa de risco associado ao relevo cárstico no município de João Pessoa/PB

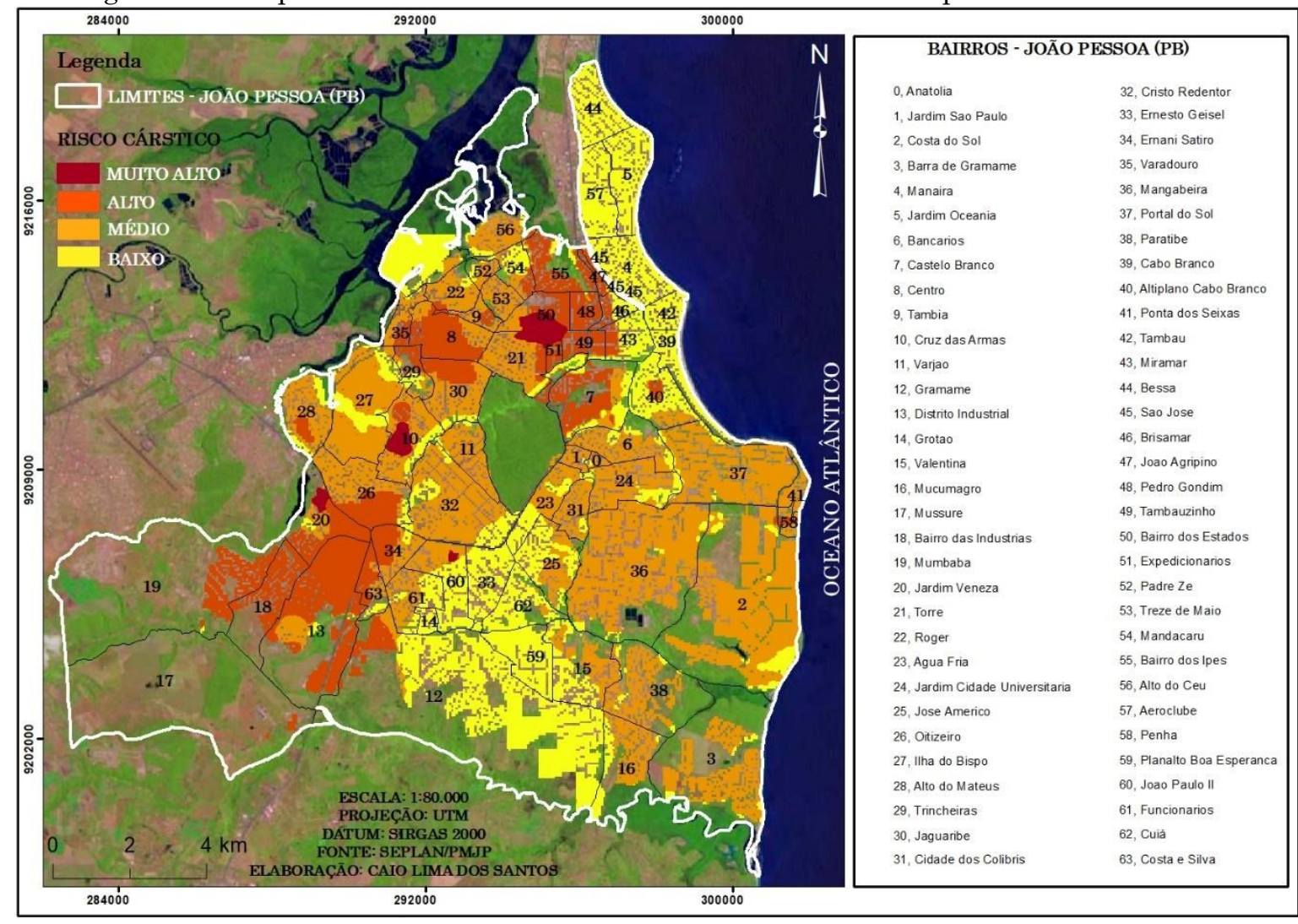

Fonte: Os autores (2021). 
O mapa de risco (Figura 08) associado aos processos cársticos no município de João Pessoa é resultado da sobreposição do mapa de suscetibilidade ao cadastro urbano do referido município. Foram definidos 4 (quatro) classes de risco a partir dos seguintes critérios:

- Risco muito alto: Corresponde a área das depressões fechadas (03, 05, 07, 09 e 12) mapeadas nesse estudo onde foi observado processo de subsidência do terreno a partir da constatação de problemas estruturais em edificações prediais localizadas no interior dessas depressões, além da constante abertura de crateras no solo associadas a eventos pluviométricos de alta magnitude.

- Risco alto: Corresponde às áreas definidas como alta suscetibilidade natural aos processos cársticos e as demais depressões mapeadas, onde não foram identificados problemas estruturais em edificações prediais no seu interior. Essas áreas estão interpostas entre as bacias fechadas atuais.

- Risco médio: Corresponde às áreas definidas como média suscetibilidade natural aos processos cársticos. Nesse contexto não é observado a ocorrência de feições cársticas atuais, no entanto, verifica-se a existência de feições cuja forma atual (cabeceiras de drenagem e anfiteatros) testemunham evolução morfodinâmica de antigas formas cársticas.

- Risco baixo: Corresponde às áreas definidas como baixa suscetibilidade natural aos processos cársticos. Essas áreas correspondem às formas deposicionais atuais, tais como as planícies fluviais e marinha, tendo em vista a não ocorrência de depressões fechadas nesses compartimentos geomorfológicos.

Desse modo, o mapa de risco considerou apenas as áreas ocupadas pelo processo de urbanização, definidas a partir dos dados cadastrais de lotes disponibilizados pela SEPLAN/PMJP (2020), desprezando áreas que predominam atividades rurais. A tabela 03 apresenta o quantitativo de lotes inseridos em cada área de risco mapeada.

Tabela 03 - Quantitativo de lotes inseridos em áreas de risco cárstico, conforme cadastro urbano do município de João Pessoa/PB.

\begin{tabular}{|c|c|}
\hline RISCO & Número total de lotes \\
\hline MUITO ALTO & 1.790 \\
\hline ALTO & 73.064 \\
\hline MÉDIO & 58.320 \\
\hline BAIXO & 60.341 \\
\hline Total & $\mathbf{1 9 3 . 5 1 5}$ \\
\hline
\end{tabular}

Fonte: Dados cadastrais cedidos pela SEPLAN/PMJP (2020).

\section{CONSIDERAÇÕES FINAIS}

A condição estrutural representa o fator preponderante para a gênese e evolução de depressões cársticas no município de João Pessoa/PB. Todas as formas mapeadas estão alinhadas preferencialmente nas direções $\mathrm{E}-\mathrm{W}$ e NE-SW, de acordo com as direções dos lineamentos mapeados na área de estudo.

$\mathrm{O}$ crescimento urbano na área promoveu fortes alterações superficiais, constituindo fator preponderante na análise dos riscos, além de promover a infiltração de fluídos para subsuperfície, tais como esgotos e efluentes domésticos, que podem atuar como potencializadores ou deflagradores do processo de dissolução das rochas carbonáticas, acelerando a criação de vazios subterrâneos que podem se manifestar superficialmente no processo de subsidência do solo, caracterizando uma situação de risco.

Considerando que o referido município encontra-se quase totalmente urbanizado, e que diversas atividades antrópicas constituem fator potencializador dos processos cársticos, é possível afirmar que a população de João Pessoa apresenta forte vulnerabilidade frente às situações de risco que podem ser geradas no desenvolvimento do relevo cárstico, considerando que os fenômenos atrelados a gênese dessas formas ocorrem em subsuperfície, mas se repercutem superficialmente, atingindo pessoas de todas as classes sociais, sem restrições. 


\section{REFERENCIAS}

AESA. Agência executiva de gestão das águas. Dados de poços tabulares da AESA, 2015.

BARBOSA, J. A. A deposição carbonática na faixa costeira Recife-Natal: aspectos estratigráficos, geoquímicos e paleontológicos. 270f. Tese (Doutorado). Programa de Pós-Graduação em Geociências. Universidade Federal de Pernambuco, 2007.

BARBOSA, T. S. Geomorfologia urbana e mapeamento geomorfológico do município de João Pessoa - PB, Brasil. 2015. 115 f. Dissertação (Mestrado em Geografia) Universidade Federal da Paraíba, João Pessoa, 2015.

BRASIL. Ministério de Minas e Energia. CPRM. Geologia e Recursos Minerais do Estado da Paraíba. Recife - PE, 2002. Escala: 1:500.000.

CAGEPA. Companhia de água e esgoto do Estado da Paraíba. Dados de poços tabulares da CAGEPA, 2015.

CPRM. Serviço Geológico do Brasil. Geologia e recursos minerais do estado da Paraíba. Organizado por Edilton José dos Santos, Cícero Alves Ferreira, José Maria Ferreira da Silva Júnior - Recife: CPRM, 2002. 142 p. il. 2 mapas. Escala 1:500.000.

CPRM. Serviço Geológico do Brasil. Sistema de informações de águas subterrâneas (SIAGAS). Disponível em http://siagasweb.cprm.gov.br/layout/visualizar_ mapa.php. Acesso em 18 jul. de 2019.

DE WAELE, J. GUTIÉRREZ, F. PARISE, M. PLAN, L. Geomorphology and natural hazards in karst areas: a review. In: Geomorphology, v. 134, n. 1-2, p. 1-8, 2011. https://doi.org/10.1016/j.geomorph.2011.08.001.

ESRI. ArcMap 10.4 2016. Versão estudante. Disponível em https://community.esri.com/www.esriportugal.pt /sitelicense. Acesso em 20 jul. de 2020.

FURRIER, M., Araújo, M. E., Meneses, L. F. Geomorfologia e Tectônica da Formação Barreiras no Estado da Paraíba. In: Revista do Instituto de Geociências - USP, v.6, n.2, p.6170 , 2006. https://doi.org/10.5327/S1519874X200600030000 8

FURRIER, M; VITAL, S. R. O. A Formação de Dolinas em Áreas Urbanas: o Caso do Bairro de Cruz das Armas em João PessoaPB. Revista Brasileira de Geografia Física, [S.l.], v. 4, n. 1, p. 161-173, set. 2011. ISSN 1984-2295. https://doi.org/10.26848/rbgf.v4i1.232672.

GOMES, M. SANTOS, D. J. RUCHKYS, Ú. A. TRAVASSOS, L. E. P. Caracterização microclimática de cavernas turísticas do Parque Nacional Cavernas do Peruaçu, Minas Gerais, Brasil. Sociedade \& Natureza, v.
33, 2021. https://doi.org/10.14393/SN-33-202158420

GUTIÉRREZ, F. GALVE, J. P. LUCHA, P. CASTAÑEDA, C. BONACHEA, J. GUERRERO, J. Integrating geomorphological mapping, trenching, InSAR and GPR for the identification and characterization of sinkholes in the mantled evaporite karst of the Ebro Valley (NE Spain). In: Geomorphology, n. 134, 144-156, 2011. https://doi.org/10.1016/j.geomorph.2011.01.018.

GUTIÉRREZ, T. PARISE, M. DE WAELE, J. JOURDE, H. A review on natural and human-induced geohazards and impacts in karst. In: Earth-Science Reviews, v. 138, p. 6188 ,

2014.

https://doi.org/10.1016/j.earscirev.2014.08.002

GUTIÉRREZ, F. Sinkhole Hazards. Oxford Research Encyclopedia of Natural Hazard Science, 2016.2 Diposnível: https://oxfordre.com/naturalhazardscience/view/ 10.1093/acrefore/9780199389407.001.0001/acref ore-9780199389407-e-40. Acesso em: 05 jul. de 2019.

https://doi.org/10.1093/acrefore/9780199389407. 013.40

HUANG, J. XUE, F. WANG, T. ZHAO, T. WANG, $X$. Karst development characteristics and collapse risk assessment along Shaoxing metro line 1. In: IOP Conference Series: Earth and Environmental Science. IOP Publishing, 2020. p. 042050. doi: 10.1088/1755$1315 / 570 / 4 / 042050$

LIRA, B. Blog do Bruno Lira. Disponível em http://www.blogdobrunolira.com.br/2019/02/crat era-engoli-carro-em-joao-pessoa/c Acesso em 19 jun de 2019.

SANTOS LOBO, H. A. Circulação microclimática entre superfície, grandes dolinas e cavernas no carste de São Desidério, Bahia. Sociedade \& Natureza, [S. l.], v. 25, n. 1, 2013. Disponível em: https://doi.org/10.1590/S198245132013000100013

LOLCAMA, J. L. COHEN, H. A. TONKIN, M. J. Deep karst conduits, flooding, and sinkholes: lessons for the aggregates industry. In: Engineering Geology, v. 65, n. 2-3, p. 151-157, 2002. https://doi.org/10.1016/S00137952(01)00122-3

MARÉCHAL, J. C. LADOUCHE, B. DÖRFLIGER, $\mathrm{N}$. Karst flash flooding in a Mediterranean karst, the example of Fontaine de Nîmes. In: Engineering Geology, v. 99, n. 3-4, p. 138-146, 2008.

https://doi.org/10.1016/j.enggeo.2007.11.013

MICROSOFT office excel 2016. Versão Microsoft office professional plus. Microsoft corporation, 2016.

NAWAZ, B. A. SPYROPOULOS, E. AL-SAAFIN, A. Kh. Risk Assessment for Karst Hazards at a Facility in Saudi Arabia-A Case Study. Journal of Geoscience and Environment 
Protection, 8, 277-312, 2020. https://doi.org/10.4236/gep.2020.85018.

PEREIRA, R. G. F. A. Caracterização Geomorfológica e Geoespelelógica do Carste da Bacia do Rio Una, Borda Leste da Chapada Diamantina (Município de Itaetê, Estado da Bahia). Dissertação de Mestrado. Instituto de Geociências USP, 1998. https://www.teses.usp.br/teses/disponiveis/44/44 134/tde21102015155053/publico/Pereira_Mestra do.pdf

PEREIRA, L. S. FARIAS, T. S. (2020). Assessing the cultural values of the geodiversity in a Brazilian city: The historical center of João Pessoa (Paraíba, NE Brazil), Mata da Aldeia chart. International Journal of Geoheritage and Parks.

https://doi.org/10.1016/j.ijgeop.2020.03.002

PORTAL G1 PARAÍBA. Disponível em https://g1.globo.com/pb/paraiba/noticia/asfaltoce deecraterasseformamemcruzamentos-aposchuvas-em-joao-pessoa.ghtml. Acesso em 18 jun de 2019.

QGIS.oRG, 2021. Sistema de Informação Geográfica QGIS. Associação QGIS. Versão 3.14. Disponível em http://www.qgis.org. Acesso em 20 jul. de 2021.

RODRIGUEZ, J. L. Acumulação de capital e produção do espaço: a caso da Grande João Pessoa. Ed. Universitária/UFPB: João Pessoa, 1980.

SEPLAN. Secretaria de planejamento da prefeitura de João Pessoa/PB. Dados cartográficos disponibilizados pela SEPLAN/JP, 2020.

SPRING: Integrating remote sensing and GIS by object-oriented data modelling" Camara G, Souza RCM, Freitas UM, Garrido J Computers \& Graphics, 20: (3) 395-403, May-Jun 1996. https://doi.org/10.1016/0097-8493(96)00008-8

SURFER, version 12. Golden Software, 2014. Conjunto de programas. (versão de teste). Disponível em http://www.goldensoftware.com. Acesso em 20 jul. de 2020.

TRAVASSOS, L. E. P. Contribuições científicas do professor Dr. Heinz Charles Kohler para a Geomorfologia Cárstica Tropical brasileira. Sociedade \& Natureza, v. 22, p. 625 637 ,

2010. https://doi.org/10.1590/S19824513201000030001 6
VESTENA, L. R. KOBIYAMA, M. SANTOS, J. C. Considerações sobre gestão ambiental em áreas cársticas. In: RA'EGA, p. 81-94, 2002. https://www.academia.edu/22755733/Considera $\% \mathrm{C} 3 \% \mathrm{~A} 7 \% \mathrm{C} 3 \% \mathrm{~B} 5 \mathrm{es}$ sobre_gest\%C3\%A3o_ambi ental_em_\%C3\%A1reas_c\%C3\%A1rsticas?from= cover_page

VITAL, S. R. O. TRAVASSOS, L. E. P. (2015a). Impactos decorrentes do uso do solo em dolinas da Bacia Sedimentar da Paraíba, zona oeste do município de João Pessoa (PB), Brasil. Caderno de Geografia, 25(44), 118133. DOI 10.5752/p.23182962.2015v25n.44p.118

VITAL, S. R. O. Análise geológicageomorfológica das depressões fechadas e dolinas em sedimentos da Formação Barreiras na região de João Pessoa (PB). 216f. Tese (Doutorado) - Programa de Pósgraduação em Geociências, Centro de Tecnologia e Geociências, Universidade Federal de Pernambuco, Recife, PE, 2015b.

VITAL, S. R. O. BARRETO, A. M. F. WILLIAM, S. F. TRAVASSOS, L. E. P. Morfologia, gênese e desenvolvimento de depressões fechadas na Bacia Sedimentar da Paraíba. William Morris Davis - Revista de Geomorfologia, v. 1, n. 2. p. 190-206, 2020 . https://doi.org/10.48025/ISSN26756900.v1n2.p1 90-206.

ZENG, J. HUANG, G. Set pair analysis for karst waterlogging risk assessment based on AHP and entropy weight. Hydrology research, v. 49, n. 4, p. 1143-1155, 2018. https://doi.org/10.2166/nh.2017.265

\section{CONTRIBUIÇÃO DOS AUTORES}

Todos os autores ofereceram substanciais contribuições científicas e intelectuais ao estudo. As tarefas de concepção e design do estudo, preparação e redação do manuscrito, bem como, revisão crítica foram desenvolvidas em grupo. O primeiro autor Caio Lima Dos Santos ficou especialmente responsável pelo desenvolvimento teórico-conceitual, coleta de dados e redação do manuscrito. O segundo autor Osvaldo Girão da Silva, pelas interpretações e análise dos dados; e o terceiro Saulo Roberto de Oliveira Vital, pelos procedimentos técnicos/metodológicos do artigo. 